\title{
Numerical Simulation of Heat Transfer from Three-dimensional Model of Human Head in Different Environmental Conditions
}

\author{
Masoud Hatami, Morteza Bayareh* \\ Department of Mechanical Engineering, Shahrekord University, Shahrekord 8818634141, Iran
}

Corresponding Author Email: m.bayareh@sku.ac.ir

https://doi.org/10.18280/ijht.370317

Received: 23 April 2019

Accepted: 10 September 2019

\section{Keywords:}

heat transfer, human head, natural convection, forced convection

\begin{abstract}
In this paper, the heat transfer from a human's three-dimensional head, exposed to the wind blowing and constant vertical heat flux of the sun is investigated. The model is simplified due to the complexity of the head and tissues of the human head. The air velocity is $2.5 \mathrm{~m} / \mathrm{s}$ $(9 \mathrm{~km} / \mathrm{h})$ and the heat flux is $1423 \mathrm{~W} / \mathrm{m}^{2}$ for the geographic conditions of Iran. The quick scheme is used to solve momentum and energy equations and SIMPLE algorithm is employed for coupling the velocity and pressure. The results demonstrate that the heat transfers from the brain to the skin surface over time and gradually leads to an increase in the surrounding temperature. It is found that the maximum temperature is related to the brain tissue for the case of natural convection heat transfer. By considering the forced convection heat transfer and the effect of radiation, it is revealed that the maximum temperature corresponds to the top of the head. The forehead (hair growth location) has significant higher temperature in the presence of incident heat flux and wind blowing than the case of natural convection heat transfer.
\end{abstract}

\section{INTRODUCTION}

In recent years, the study on heat transfer from the brain has increased. Generally, the heat transfer from the brain occurs in two ways. Some of studies considered the heat transfer inside the tissues and some other investigations explored the flow pattern outside the body without modeling the heat transfer within the tissue. Foturaie et al. [1] simulated the temperature distribution in the human head and convection heat transfer with the surrounding. The "Pennes" equation is a well-known thermal conduction equation in which heat generation in the living tissue is due to two sources of heat generation by metabolism and blood supply. They used a two-dimensional model of human head at the middle of the sagittal using a human's actual anatomy to examine the heat transfer within the living tissues and its effect on natural convection heat transfer around the human head. Their results showed that the maximum temperature and the minimum one occurs in the brain and nasal area, respectively. Also, they showed that the maximum Nusselt number occurs in the front of the head and its minimum happens at its upper edge.

Frijns et al. [2] modeled the heat transfer in the human body. The temperature plays a very important role in the performance of biological systems. In order to predict the temperature of the living tissue, blood flow should be taken into account. The subject of this study was that the cooling of the scalp prevents hair loss due to chemotherapy. In the calculation of the overall temperature distribution, the mechanism for regulating the temperature of transpiration, vibration etc. should be taken into account. Clark and Toy [3] studied natural convection heat transfer around the human head. In this study, the patterns of convection flow around the human head in a relaxed state and in relation to body state were discussed. Their results indicated that the layer of air around the head for the standing position of the body is thicker than that for the rest of the body. Zeinali and As'adi [4] studied the distribution of temperature within the head of the human body and the air around the head. In this study, they used the Pennes equation to study the heat transfer within the human head. A two-dimensional model of human head was simulated using the finite volume method. Clark and Toy [5] experimentally demonstrated that the distribution of local forced heat transfer between the head and a vibrant vertical cylinder are roughly similar and dependent on aerodynamic flow patterns at different wind speeds. Ferreira and Yanagihara [6] presented a transient three-dimensional model of heat transfer in the human body. The goal was to develop an improved model of the human body's thermal system.

Since three-dimensional flow around the human head is similar to the flow around the bluff bodies, it is important to consider the previous investigations who considered heat transfer and fluid flow past the bluff bodies or vortex generators [5, 7-12]. For example, Arif and Hasan [7] studied the flow around a square cylinder and analyzed the vortex shedding phenomena considering effective parameters. Bayareh et al. [12] investigated the effect of vortex generator on heat transfer of a flat plate and demonstrated that as the angle of vortex generator increases, the longitudinal vortices become stronger.

The present study aims to simulate the heat transfer from a human's three-dimensional head, exposed to the wind and steady vertical heat flux of the sun. The most of the abovementioned works investigated two-dimensional heat transfer from human head. The present results will actually become closer to the reality. On the other hand, in most of the abovementioned works, the heat transfer is considered to be a 
transition from the head, and the head is cooling and exchanging heat with the environment. In this paper, in addition to exchanging the heat of the head with the environment, the head is exposed to the sun's radiation. In fact, the boundary conditions are similar to the actual conditions of the environment.

\section{PROBLEM DESCRIPTION}

In the present study, the heat transfer from a human's three-dimensional head exposed to the wind blowing (the breeze) and constant vertical flux of the sun is investigated numerically (Figure 1). The model is simplified due to the complexity of the head and tissues of the human head. In fact, the purpose is to study the effects of head geometry and heat transfer and temperature changes of the brain. In these simulations, the scalp, brain, mouth and eyes are modeled. Muscle properties are used to model other parts of the human brain.

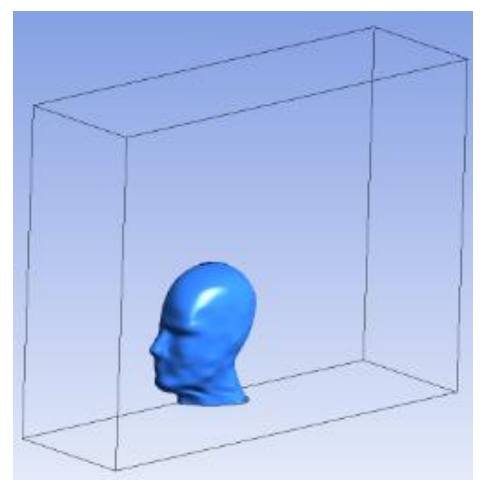

(a)

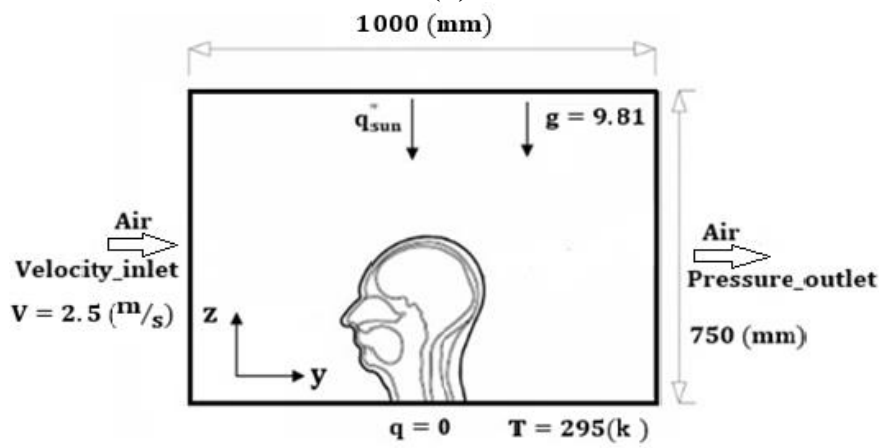

(b)

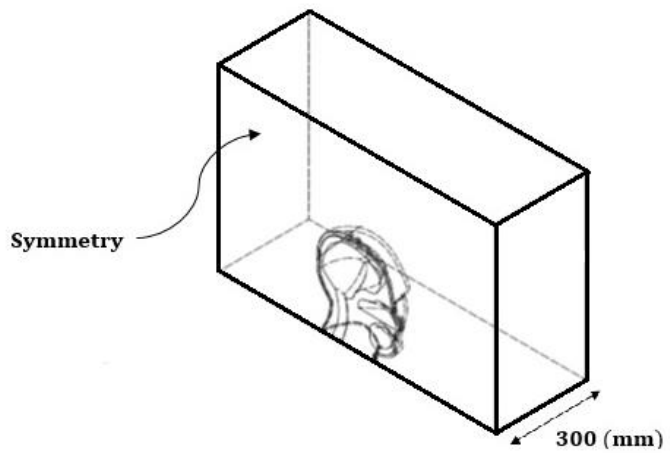

(c)

Figure 1. The schematic of the present problem: (a) Threedimensional view, (b) The two-dimensional view with the visibility of the face along with the boundary conditions, and

(c) Three-dimensional view of the head along with the boundary conditions

\section{GOVERNING EQUATIONS}

\subsection{Governing equations for a living tissue}

In the present work, the heat transfer from the human's three-dimensional head exposed to wind blowing (forced convection heat transfer) and the steady vertical heat flux of the sun is studied. For live tissues, for example, human head, the known model of Pennes is used to model the heat transfer from blood diffusion. In the absence of convection and radiation heat transfer in the head, the heat transfer equation is as follows [13]:

$$
\rho C_{p} \frac{\partial T}{\partial t}=\Delta k(\nabla T)+q_{b}+q_{m}
$$

Pennes considered two sources of internal heat generation for a living tissue: heat generation from blood perfusion $\left(\mathrm{q}_{\mathrm{b}}\right)$ and heat generation from metabolism $\left(\mathrm{q}_{\mathrm{m}}\right)$. In this model, the distribution of velocity and temperature in all parts of the surrounding ambient model is derived from the application of the heat production conditions. Therefore, it is important to determine their value and dependence. $\mathrm{q}_{\mathrm{b}}$ is the amount of energy generated or rejected per unit volume of tissue, which is controlled by blood to maintain a central body temperature in a biological equilibrium. According to the model provided by Pennes, the amount of this energy is proportional to the difference between the temperature of the center of the tissue and the temperature of its surface and also the rate of blood penetration in the tissue. This expression is presented as the following equation [14]:

$$
\mathrm{q}_{\mathrm{b}}=\mathrm{M}_{\mathrm{p}} \mathrm{C}_{\mathrm{p}}\left(\mathrm{T}_{\mathrm{art}}-\mathrm{T}\right)
$$

where, $\mathrm{T}$ is the temperature of the living tissue, $\mathrm{T}_{\text {art }}$ is the blood temperature distributed in the tissue, $\mathbf{M}_{\mathrm{p}}$ is the mass penetration rate per unit volume of tissue and $C_{p}$ is the specific heat of the blood. $\mathrm{M}_{\mathrm{p}}$ depends on the capillary bed in the tissue. Also, $\mathrm{q}_{\mathrm{m}}$ is the production capacity per unit volume due to the metabolic activity of cells throughout the living tissue, which in this paper is considered uniform due to small changes in the temperature of the brain and as a source of the same heat production per unit volume in all living tissue models. In addition, the thermal effect of blood flow throughout the tissue is considered uniformly and isotropic in the present study [15-17]. Table 1 is used to determine the values of physical and physiological parameters for tissues, which include thermal conductivity, density, specific heat, mass permeation rate per unit volume of tissue and production capacity per volume unit. Due to the fact that the head is exposed to the steady vertical heat flux of the sun, the absorption coefficient $(\alpha)$ and the emissivity $(\varepsilon)$ of the skin are also presented.

\subsection{Governing equations for the air flow around the head}

Natural convection heat transfer from the head due to the difference between the surface temperature and ambient temperature is a phenomenon that the human body has always faced and has been the subject of various medical and vital considerations [16-19]. In this phenomenon, during the heat transfer from head to the environment, adjacent air becomes warmer, its density decreases and moves upward [20]. The approximate thickness of the thermal boundary 
layer, the air velocity in the surface layers, and the amount of heat transfer at certain points of the head were measured by Clark and Toy [3] and compared with the results of heat transfer from a cylinder with an equivalent size. Clark and
Toy [5] also investigated the heat transfer of forced convection around the human head in a wind tunnel and found that the heat transfer around the head and an equalsized vertical cylinder is approximately the same.

Table 1. Thermophysical properties for different tissues [1]

\begin{tabular}{cccccccc}
\hline Tissue & $\boldsymbol{\alpha}$ & $\boldsymbol{\varepsilon}$ & $\boldsymbol{q}_{\boldsymbol{m}}$ & $\boldsymbol{M}_{\boldsymbol{p}}$ & $\boldsymbol{C}_{\boldsymbol{p}}$ & $\boldsymbol{\rho}$ & $\boldsymbol{k}$ \\
& & & $W / m^{2}$ & $K g / m^{3} . s$ & $J / k g . K$ & $K g / m^{3}$ & $W / m K$ \\
\hline Skin & 0.95 & 0.95 & 33 & 0.433 & 2495 & 1480 & 0.34 \\
Muscle & - & - & 33 & 0.433 & 3543 & 1040 & 0.52 \\
Bone & - & - & 5 & 0.066 & 1500 & 1600 & 1.16 \\
Brain & - & - & 525 & 8.6 & 3680 & 1000 & 0.52 \\
Cartilage & - & - & 0 & 0 & 3680 & 1000 & 0.52 \\
\hline
\end{tabular}

It should be pointed out that, in this paper due to the wind blowing (the breeze) and the steady vertical heat flux of the sun, the heat transfer between the head and the surrounding area is carried out as a forced convective heat transfer. Therefore, the relationship between the energy conservation in the tissue is coupled to the continuity, momentum and energy equations in the fluid around the head. The boussinesq approximation is used for density variations with the temperature. Hence, the governing equations for the fluid around the head are as follows [21]:

Continuity equation:

$$
\nabla \cdot \mathrm{V}=0
$$

Momentum equation:

$$
\rho \mathrm{V} \cdot \Delta \mathrm{V}=-\Delta \mathrm{P}+\mu \nabla^{2} \mathrm{~V}+\rho g \beta\left(\mathrm{T}-\mathrm{T}_{\mathrm{a}}\right)
$$

Energy equation:

$$
\rho \mathrm{C}_{\mathrm{p}} \mathrm{V} \nabla \mathrm{T}=-\mathrm{k} \nabla^{2} \mathrm{~T}
$$

In these relations, $\mathrm{V}$ is the velocity, $\mathrm{P}$ is the pressure, $\beta$ is the thermal expansion coefficient, $\mathrm{g}$ is the acceleration due to the gravity, $\mathrm{k}$ is the thermal conductivity coefficient, $\mathrm{T}_{\mathrm{a}}$ is the reference temperature for calculating the fluid density, and $\mathrm{Cp}$ is the fluid heat capacity. Table 2 shows the values of these parameters for air at $23{ }^{\circ} \mathrm{C}$, which is considered as ambient temperature in this paper.

\section{INITIAL AND BOUNDARY CONDITIONS}

According to figure1, the fluid velocity at the boundary of the tissues is zero (no-slip boundary condition). The stress on the lateral boundary is zero (slip boundary condition) and the inlet flow temperature is $295 \mathrm{~K}$. The boundary along the head (the boundary in the direction of the $\mathrm{x}$-axis) is wall with the temperature of $295 \mathrm{~K}$. The upper surface is chosen as the source of steady vertical heat flux. The heat flux is 1423 $\mathrm{W} / \mathrm{m}^{2}$ for the geographic conditions of Iran.

Since the human head is summitry, one can consider half of the head for simulations. Here, the head is exposed to the wind (forced convection heat transfer). Therefore, the air enters at the velocity of $2.5 \mathrm{~m} / \mathrm{s}(9 \mathrm{~km} / \mathrm{h})$ and goes out the boundary by passing through the head. These conditions permit the entrance of the air to the model from the boundary behind the front and exit from the front of the face.

The initial value of the temperature is assumed to be $295 \mathrm{~K}$ in order to determine the ambient temperature. On the other hand, the initial temperature of the body or living tissue is $310 \mathrm{~K}$.

Table 2. Physical properties of Air at $23{ }^{\circ} \mathrm{C}$ [21]

\begin{tabular}{cc}
\hline $\mathbf{k}(\mathbf{W} / \mathbf{m K})$ & 0.0263 \\
\hline $\boldsymbol{\rho}\left(\mathbf{K g} / \mathbf{m}^{\mathbf{3}}\right)$ & 1.1414 \\
$\boldsymbol{\mu}\left(\mathbf{N s} / \mathbf{m}^{\mathbf{2}}\right)$ & $1.846 \times 10^{-5}$ \\
$\boldsymbol{\beta}(\mathbf{1} / \mathbf{K})$ & 0.0033 \\
$\mathbf{C}_{\mathbf{p}}(\mathbf{J} / \mathbf{k g} . \mathbf{K})$ & 1007 \\
\hline
\end{tabular}

\section{NUMERICAL METHOD}

The governing equations are solved using a finite volume method [22-25]. The quick scheme is used to solve momentum and energy equations and SIMPLE algorithm is employed for coupling the velocity and pressure [26-30]. To avoid the instability of the answer, the time-dependent method is used. For this purpose, the first-order Eulerian implicit algorithm is used with a time interval of 0.1 .

\section{RESULTS}

The results of Zeinali and As'adi [4] are used to validate the results obtained from the present simulations. The distribution of temperature on the external boundary of the head is plotted and compared with the results of Zeinali and As'adi [4]. The temperature of the central core is considered as $37{ }^{\circ} \mathrm{C}$ and other boundary conditions are in accordance with Zeinali and As'adi [4].

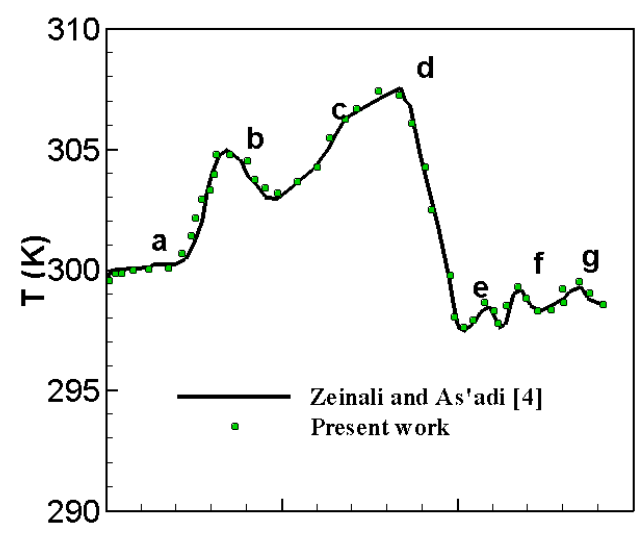

Figure 2. Temperature distribution around the hea 
Figure 2 shows the temperature distribution diagram on the external boundary of the head. The maximum value of the temperature obtained from the simulations is $307.5 \mathrm{~K}$. Zeinali and As'adi [4] reported the value of $308 \mathrm{~K}$. The reason for this small amount of error is due to that their twodimensional simulations. On the other hand, the variations of temperature are similar for both simulations. It can be seen that the maximum skin temperature occurs at the forehead (hair growth location) and the minimum one takes place on the nose.

In this paper, different computational grids are considered for performing the simulations. The grid resolutions are 1864649 (large mesh), 2138135 (normal mesh), and 3118657 (tiny mesh). Average Nusselt number is calculated on external boundary of the head for different grid resolutions (Figure 3). It is found that the error for the grid resolutions of 2138135 and 3118657 is $5.5 \%$ and $5.1 \%$ compared to the one of 1864649, respectively. Hence, the grid resolution of 2138135 is selected for further simulations.

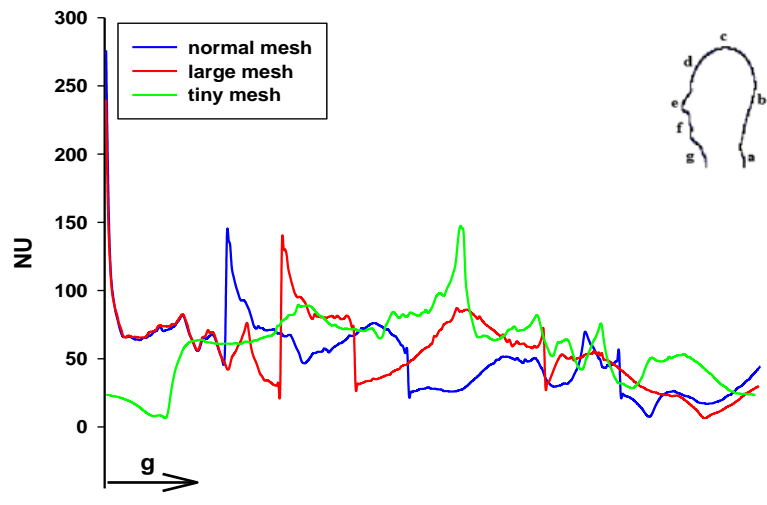

Figure 3. Average Nusselt number is calculated on external boundary of the head for different grid resolutions

\subsection{Three-dimensional model of the head exposed to the surrounding air}

Initially, the results of the three-dimensional simulations are presented based on the two-dimensional model of Zeinali and As'adi [4]. The boundary conditions are the same as the ones of Zeinali and As'adi [4]. In Figure 4, the contours of temperature distribution are shown on the symmetry plane of $X=0$ at the times of 10,30 , and 50 minutes. It can be seen that over time, the heat transfers from the brain to the skin surface and gradually leads to an increase in the surrounding temperature. It is also found that the maximum temperature is related to the brain tissue, which is the same temperature as the core of the body or the blood temperature distributed in the living tissue $(310 \mathrm{~K})$. Gradually, the temperature of the other tissues is reduced in comparison with the brain temperature. However, the temperature of all tissues increases with the time. For example, the nose is approximately at $297 \mathrm{~K}$ and $303 \mathrm{~K}$ after 10 and 50 minutes, respectively. It can be observed that cartilage in the nasal area has the minimum temperature. This is due to three reasons: i) no heat generation in this area $\left(\mathrm{q}_{\mathrm{m}}=0\right)$, ii) the distance from the brain and iii) the nose has high contact with the surrounding air. It is also observed that the thickness of the thermal boundary layer in front of the head is larger than that in the behind the head. The interference of these two thermal boundary layers (front and back) causes a jet-like flow above the head. As the head temperature increases, the thickness of these boundary layers and jet flow are also increased.

The maximum temperature on the head shell corresponds to the overhead. The temperature of this region is approximately $304 \mathrm{~K}$ after 30 minutes and $306 \mathrm{~K}$ after 50 minutes. It can be seen that the temperature of thermal boundary layer has also increased with time due to the enhancement in the temperature of the head and the heat transfer from the head to the environment. For example, the temperature of the thermal boundary layer is about $300 \mathrm{~K}$ after 30 minutes and $303 \mathrm{~K}$ after 50 minutes.

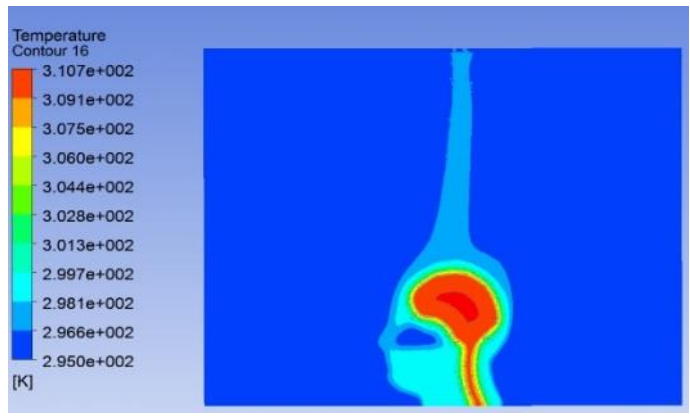

(a)

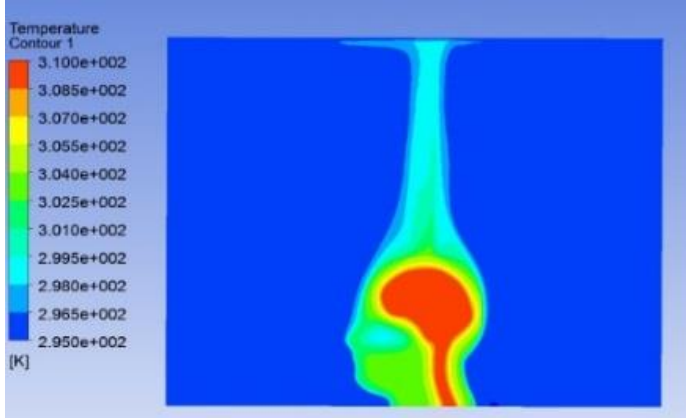

(b)

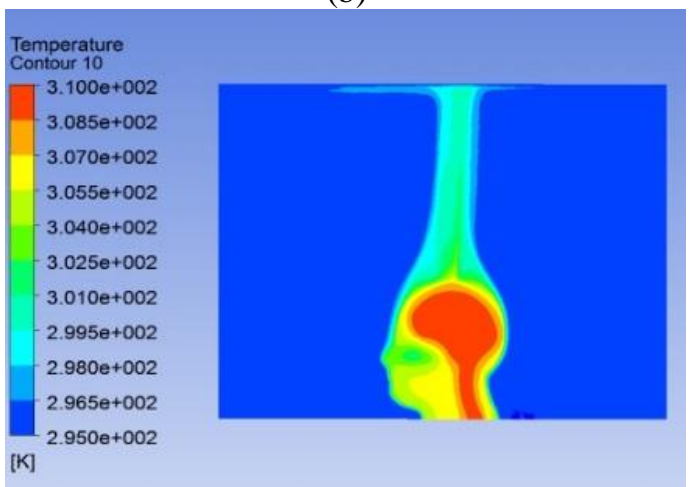

(c)

Figure 4. Temperature distribution for inside and outside the head on symmetry plane $(\mathrm{x}=0)$ after the time: (a) 10 minutes,

(b) 30 minutes, and (c) 50 minutes

In Figure 5, the temperature distribution on the external boundary of the head (shell) is presented at three different times. It can be seen that the temperature of each tissue has increased over time. The increase from 10 to 30 minutes is much higher than that from 30 to 50 minutes. For example, the maximum temperature occurs at the forehead (point $d$ ). Because the distance between the brain and the shell is low in this part, and the thickness of the thermal layer in front of the head is more than that in its behind. The minimum temperature takes place at the nose (point e). Because there is no energy generation in this part $\left(\mathrm{q}_{\mathrm{m}}=0\right)$. This result is 
expected due to the high heat transfer rate between the brain and its surrounding air. The temperature at the tissues behind the head (points a and b) is much higher than that at tissues in front of the head (points $g, f$ and e).

The average Nusselt number is plotted on the external boundary of the head (shell) at different times (Figure 6). According to the figure, the variations of Nusselt number are quite reasonable. It is seen that the maximum Nusselt number corresponds to the forehead (point d) and its minimum is related to the nose (point e).

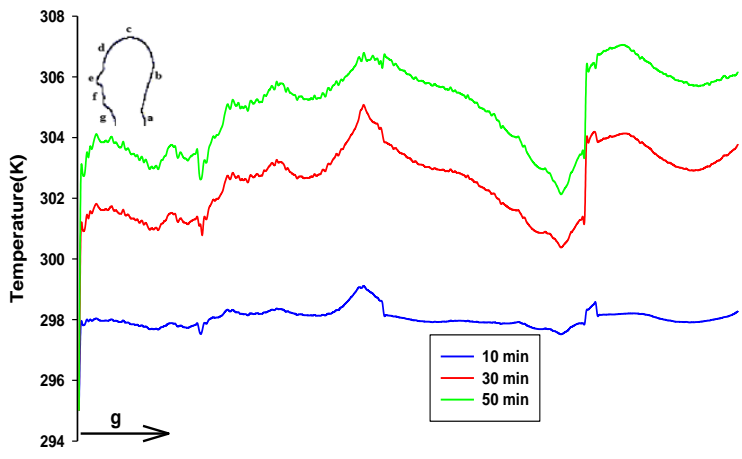

Figure 5. Temperature distribution on external boundary of head at different times

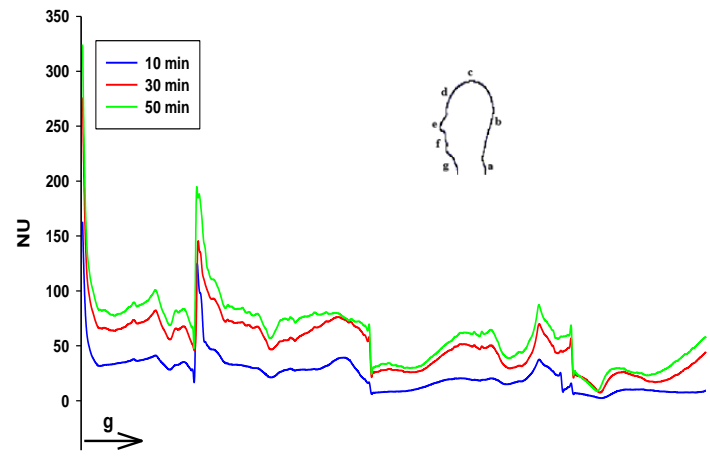

Figure 6. Average Nusselt number on external boundary of head at different times

\subsection{Effects of forced convection heat transfer and constant vertical radiation}

In this section, heat transfer from the human's threedimensional head exposed to the wind blowing (forced convection heat transfer) and constant vertical radiation is investigated. The wind velocity is $2.5 \mathrm{~m} / \mathrm{s}$ and the heat flux is $1423 \mathrm{~W} / \mathrm{m}^{2}$. Figure 7 shows the temperature distribution contours for the head and its surrounding area on the symmetry plane $(x=0)$ at different times. It can be seen that the brain does not have the maximum temperature due to the presence of constant heat flux. In fact, the maximum temperature corresponds to the top of the head, which is exposed to the incident constant heat flux. For example, after 50 minutes, the brain has a temperature of $310 \mathrm{~K}$, while the top of the head has the maximum temperature of $349 \mathrm{~K}$. This very high temperature is due to the direct radiation of the constant vertical heat flux. On the other hand, due to the incident heat flux, the nose is exposed to the radiation and its temperature increases.
It should be mentioned that the nasal tissue is still at the least temperature due to no energy generation $\left(\mathrm{q}_{\mathrm{m}}=0\right)$ and also because of its large distance from the brain and high contact surface with the surrounding. It can be observed that the maximum temperature increases over time and more exposed to the sun's radiation. For example, the maximum temperature is $323.6,342.3$, and $349.3 \mathrm{~K}$ after 10 , 30, and 50 minutes, respectively.

Also, the effect of wind blowing is well observed in the figure. The wind or the breeze is blowing at a speed of 2.5 $\mathrm{m} / \mathrm{s}$ from the back to the front of the head. It is found that there is no jet flow above the head. This is due to wind or breeze. Because the wind causes the thermal boundary to be drawn to the front of the head and nose. It is seen in the figure that the thermal boundary layer is thicker in the forehead.

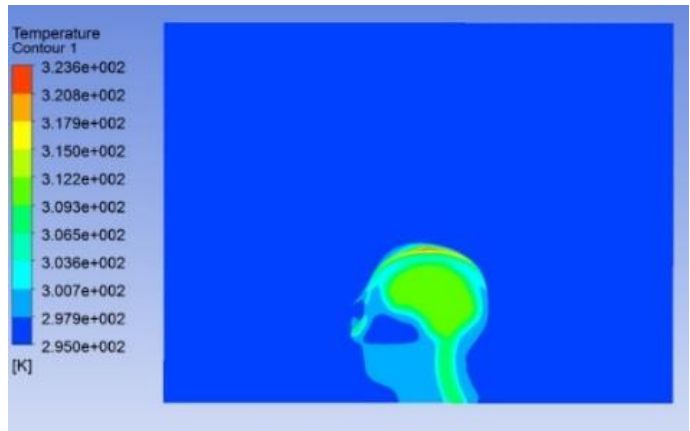

(a)

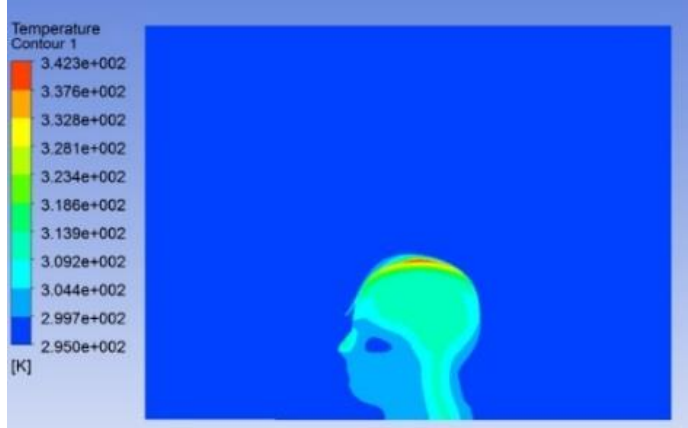

(b)

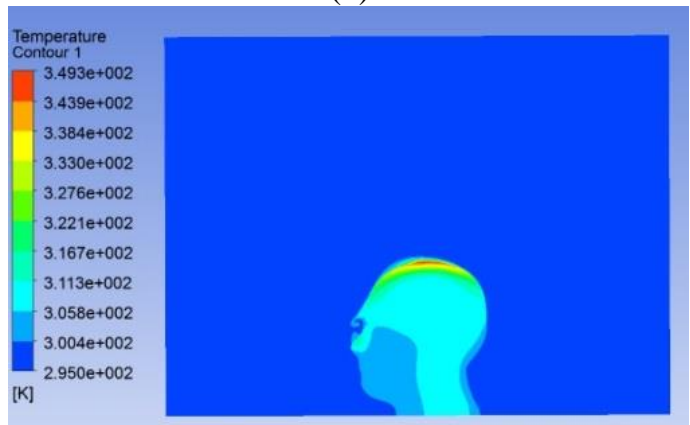

(c)

Figure 7. Temperature distribution for inside and outside the head on symmetry plane $(\mathrm{x}=0)$ in the presence of incident heat flux and wind blowing after the time: (a) 10 minutes, (b) 30 minutes, and (c) 50 minutes

Figure 8 shows the temperature distribution on the external boundary of the head at different times. It can be seen that the temperature of the tissues increases over time due to more sun exposure and the more internal heat generation. There are two peak peaks in the digram. These points correspond to the 
top of the head (point c) and forehead (point d), which are subject to direct radiation of the constant heat flux.

It is observed that the temperature of the region behind the head (points a and b) is higher than that of its front. Because the brain distance from the shell surface is smaller in this region than other ones. Hence, more heat reaches this area. It is expected that the temperature of the points $a$ and $b$ is less than the facial area due to the wind blowing from behind. However, this phenomenon does not occur. This is due to that the wind has the same temperature as the ambient air. In fact, the wind does not have any effect on the cooling of the head and only prevents the formation of thermal boundary layer and the jet flow above the head.

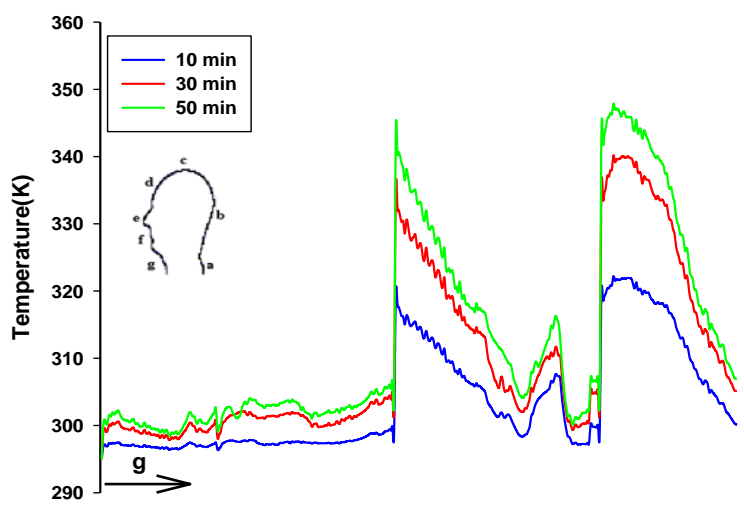

Figure 8. Temperature distribution on external boundary of head in the presence of incident heat flux and wind blowing at different times

Figure 9 shows the average Nusselt number on the external boundary of the head at different times. The variations of this figure are completely logical according to the temperature distribution changes. The maximum amount of Nessult number corresponds to the top of the head (point c), and then at the point $d$. It can also be seen that the Nusselt number increases with time and temperature enhancement. The minimum average Nusselt number does not occur in the nasal area. Because the nose is exposed to incident heat flux and so its temperature increases. According to the figure, the minimum Nusselt number corresponds to the place below the chin (point $\mathrm{g}$ ). This is due to larger distance of this point from the central heating (the brain) and no gain of constant vertical radiation compared to other regions.

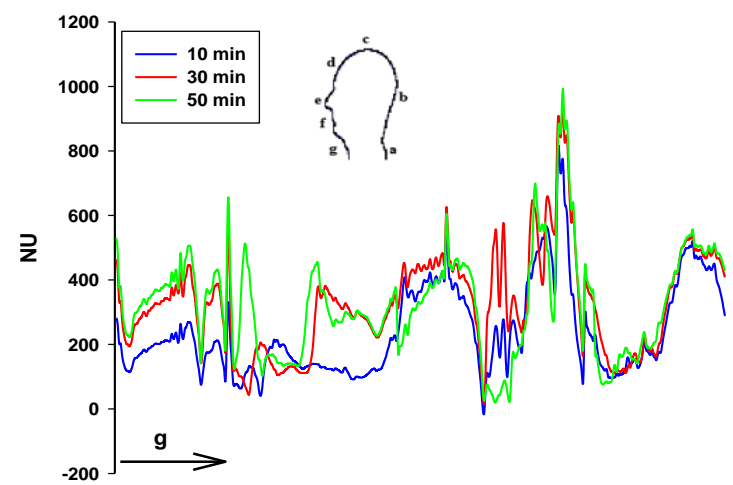

Figure 9. Average Nusselt number on external boundary of head in the presence of incident heat flux and wind blowing at different times
In order to compare the effect of two conditions mentioned in previous sections on heat transfer rate, the temperature values are presented in Table 3 after 10 and 50 minutes for different regions of the head. For example, at 10 minutes, the nose surface has a nearly identical temperature for two cases. The forehead (hair growth location) has significant higher temperature in the presence of incident heat flux and wind blowing than the case of natural convection heat transfer. This is due to that it is exposed to the incident heat flux in the second case. This is also valid for top of the head for the same reason. But, the difference between the temperatures in this section is much higher for two cases. There is no considerable difference in the temperature of back of the head. Because this region does not gain considerable heat flux from the sun, and it is only affected by the heat generation of the brain.

Table 3. The temperature values at different points of the head after 10 and 50 minutes for two cases: case 1 (natural convection heat transfer) and case 2 (forced convection heat transfer and constant heat flux)

\begin{tabular}{|c|c|c|c|c|}
\hline & \multicolumn{4}{|c|}{ Temperature } \\
\hline c & $10 \mathrm{~min}$ & $10 \mathrm{~min}$ & $50 \mathrm{~min}$ & $50 \mathrm{~min}$ \\
\hline & Case 1 & Case 2 & Case 1 & Case 2 \\
\hline $\mathrm{a}$ & 297.61 & 299.07 & 300.00 & 300.26 \\
\hline $\mathrm{b}$ & 297.61 & 305.88 & 304.00 & 316.12 \\
\hline $\mathrm{c}$ & 298.13 & 320.84 & 306.01 & 340.90 \\
\hline d & 298.13 & 298.72 & 304.00 & 305.55 \\
\hline
\end{tabular}

\section{CONCLUSIONS}

This paper investigated the heat transfer from a human's three-dimensional head, exposed to the wind and steady vertical heat flux of the sun. The model is simplified due to the complexity of the head and tissues of the human head. The heat flux was $1423 \mathrm{~W} / \mathrm{m}^{2}$ for the geographic conditions of Iran. The quick scheme is used to solve momentum and energy equations and SIMPLE algorithm is employed for coupling the velocity and pressure. Natural convection heat transfer: it was revealed that the heat transfers from the brain to the skin surface over time and gradually leads to an increase in the surrounding temperature. It was also found that the maximum temperature is related to the brain tissue, which is the same temperature as the core of the body or the blood temperature distributed in the living tissue $(310 \mathrm{~K})$. The maximum temperature on the head shell corresponded to the overhead. The temperature of this region was approximately $304 \mathrm{~K}$ after 30 minutes and $306 \mathrm{~K}$ after 50 minutes. Forced convection heat transfer and constant incident heat flux: it was demonstrated that the brain does not have the maximum temperature due to the presence of constant heat flux. The maximum temperature corresponded to the top of the head, which was exposed to the incident constant heat flux. The forehead (hair growth location) has significant higher temperature in the presence of incident heat flux and wind blowing than the case of natural convection heat transfer. There is no considerable difference in the temperature of back of the head. 


\section{REFERENCES}

[1] Foturaie, N., Pashaee, A., Nabaei, M., Atae, G. (2005). Simulation of human heat transfer with ambient air to evaluate its proper ventilation. Journal of Medical Department, 63: 463-472. (in Persian).

[2] Frijns, A., van Leeuwen, G.M.J., van Steenhoven, A.A., (2006). Modelling heat transfer in humans. ERCOFTAC Bull, 68: 43-47.

[3] Clark, R., Toy, N. (1975). Natural convection around the human head. The Journal of Physiology, 244: 283293. http://dx.doi.org/10.1113/jphysiol.1975.sp010797

[4] Zeinali Heris, S., As'adi, S. (2013). Study of temperature distribution inside the human's head and its surrounding air. Journal of Mechanical Engineering, 22: 40-51. (in Persian).

[5] Clark, R., Toy, N. (1975). Forced convection around the human head. The Journal of Physiology, 244: 295-302. http://dx.doi.org/10.1113/jphysiol.1975.sp010798

[6] Ferreira, M., Yanagihara, J.I. (2009). A transient threedimensional heat transfer model of the human body. International Communications in Heat and Mass Transfer, 36: 718-724. http://dx.doi.org/10.1016/j.icheatmasstransfer.2009.03.0 10

[7] Arif, M.R., Hasan, N. (2019). Vortex shedding suppression in mixed convective flow past a square cylinder subjected to large-scale heating using a nonBoussinesq model. Physics of Fluid, 31: 023602. https://doi.org/10.1063/1.5079516

[8] Parveez, M., Dhiman, A.K., Harmain, G.A. (2018). Influence of height ratio on flow and heat transfer around trapezoidal geometry (a generic sharp-edged body) covering transition to periodic flow. International Journal of Heat and Mass Transfer, 124: 1285-1309. https://doi.org/10.1016/j.ijheatmasstransfer.2018.03.105

[9] Derakhshandeh, J.F., MahbubAlam, M. (2019). A review of bluff body wakes. Ocean Engineering, 182: $475-488$ https://doi.org/10.1016/j.oceaneng.2019.04.093

[10] Jahanbakhshi, A., Nadooshan, A.A., Bayareh, M. (2018). Magnetic field effects on natural convection flow of a non-Newtonian fluid in an L-shaped enclosure. Journal of Thermal Analysis and Calorimetry, 133(3): 1407-1416. https://doi.org/10.1007/s10973-018-7219-6

[11] Bayareh, M., Pordanjani, A.H., Nadooshan, A.A., Dehkordi, K.S. (2016). Numerical study of the effects of stator boundary conditions and blade geometry on the efficiency of a scraped surface heat exchanger. Applied Thermal Engineering, 113: 1426-1436. https://doi.org/10.1016/j.applthermaleng.2016.11.166

[12] Bayareh, M., Nourbakhsh, A., Khadivar, M.E. (2018). Numerical simulation of heat transfer over a flat plate with a triangular vortex generator. International Journal of Heat and Technology, 36(4): 1493-1501. https://doi.org/10.18280/ijht.360443

[13] Pennes, H.H. (1948). Analysis of tissue and arterial blood temperatures in the resting human forearm. Journal of Applied Physiology, 1: 93-122. http://dx.doi.org/10.1152/jappl.1948.1.2.93

[14] Adams, R., Koster, R. (2008). Burning issues: Early cooling of the brain after resuscitation using burn dressings. A proof of concept observation, Resuscitation, 78:

$146-150$ http://dx.doi.org/10.1016/j.resuscitation.2008.03.005

[15] Motamedi, G.K., Salazar, P., Smith, E.L., Lesser, R.P., Webber, W.R., Ortinski, P.I. (2006). Termination of epileptiform activity by cooling in rat hippocampal slice epilepsy models. Epilepsy Research, 70: 200-210. http://dx.doi.org/10.1016/j.eplepsyres.2006.05.001

[16] Weihs, W., Krizanac, D., Sterz, F., Sipos, W., Högler, S., Janata, A. (2010). Outcome after resuscitation using controlled rapid extracorporeal cooling to a brain temperature of $30{ }^{\circ} \mathrm{C}, 24^{\circ} \mathrm{C}$ and $18{ }^{\circ} \mathrm{C}$ during cardiac arrest in pigs. Resuscitation, 81: 242-247. https://doi.org/10.1016/j.resuscitation.2009.11.002

[17] Kanawaku, Y., Kanetake, J., Komiya, A., Maruyama, S., Funayama, M. (2007). Computer simulation for postmortem cooling processes in the outer ear. Legal Medicine, 9: 55-62 http://dx.doi.org/10.1016/j.legalmed.2006.09.006

[18] Osorio, I., Chang, F.C., Gopalsami, N. (2009). Seizure control with thermal energy: Modeling of heat diffusivity in brain tissue and computer-based design of a prototype mini-cooler. Epilepsy \& Behavior, 16: 203211. http://dx.doi.org/10.1016/j.yebeh.2009.08.014

[19] Cappelle, B., Shtyrov, Y., Pulvermüller, F. (2010). Heating up or cooling up the brain? MEG evidence that phrasal verbs are lexical units. Brain and language, 115: 189-201. http://dx.doi.org/10.1016/j.bandl.2010.09.004

[20] Hynynen, K., McDannold, N., Clement, G., Jolesz, F. A., Zadicario, E., Killiany, R. (2006). Pre-clinical testing of a phased array ultrasound system for MRIguided noninvasive surgery of the brain - a primate study. European Journal of Radiology, 59: 149-156. https://doi.org/10.1016/j.ejrad.2006.04.007

[21] Bergman, T.L., Incropera, F.P. (2011). Fundamentals of Heat and Mass Transfer. John Wiley \& Sons.

[22] Goodarzi, Z., Ahmadi Nadooshan, A., Bayareh, M. (2018). Numerical investigation of off-centre binary collision of droplets in a horizontal channel. Journal of the Brazilian Society of Mechanical Sciences and Engineering, 40: 1-10. http://dx.doi.org/10.1007/s40430-018-1075-y

[23] Armandoost, P., Bayareh, M., Nadooshan, A.A. (2018). Study of the motion of a spheroidal drop in a linear shear flow. Journal of Mechanical Science and Technology, 32: 2059-2067. http://dx.doi.org/10.1007/s12206-018-0415-2

[24] Bayareh, M., Mortazavi, S. (2011). Effect of density ratio on the hydrodynamic interaction between two drops in simple shear flow. Iranian Journal of Science and Technology, 35: 441-452. https://doi.org/10.22099/ijstm.2011.900

[25] Bayareh, M., Mortazavi, S. (2013). Equilibrium position of a buoyant drop in Couette and Poiseuille flows at finite Reynolds numbers. Journal of Mechanics, 29: 5358. http://dx.doi.org/10.1017/jmech.2012.109

[26] Bayareh, M., Mortazavi, S. (2009). Geometry effects on the interaction of two equal-sized drops in simple shear flow at finite Reynolds numbers. 5th International Conference: Computational Methods in Multiphase Flow, WIT Trans. Eng. Sci., 63: 379-388.

[27] Bayareh, M., Mortazavi, S. (2010). Migration of a drop in simple shear flow at finite Reynolds numbers: size and viscosity ratio effects. Proceeding of International Conference on Mechanical, Industriel and Manufacturing Engineering (ICMIME), Cape Town, 
South Africa.

[28] Mohammadi Masiri, S., Bayareh, M., Ahmadi Nadooshan, A. (2019). Pairwise intercation of drops in shear-thinning inelastic fluids. Korea-Australia Rheology Journal, 31(1): 25-34. https://doi.org/10.1007/s13367-019-0003-8
[29] Bayareh, M., Dabiri, S., Ardekani, A.M. (2016). Interaction between two drops ascending in a linearly stratified fluid. European Journal of MechanicsB/Fluids, 60 :

127-136. http://dx.doi.org/10.1016/j.euromechflu.2016.07.002 